\title{
DESIGNING AND OPTIMIZATION OF A MOBILE CROP RESIDUE DISINTEGRATOR BY USING BOX BEHNKEN RSM METHOD
}

\author{
Nilesh Awate \\ Research Scholar, Department of Mechanical Engineering, \\ G. H. Raisoni College of Engineering Nagpur, India \\ Dr. D.J. Tidke \\ Ex Professor, Department Mechanical Engineering, \\ G.H. Raisoni College of Engineering Nagpur, India
}

\begin{abstract}
The most commonly used designs to determine response surfaces are the full and fractional factorial designs and the more complex central composite, Box-Behnken, Doehlert and mixture designs. Although the factorial designs can be used to determine simple response surfaces that are linear in all of the investigated factors, they are normally used to determine which experimental factors are the most important to investigate and which factors do not significantly affect the experimental results. The more important the interaction term, the greater is the degree of twisting the planar response surface experiences. If the linear model is not sufficient to represent the experimental data adequately, more experiments can be performed in addition to those of factorial design. The Box-Behnken and Doehlert designs can also be used to determine these kinds of response surfaces and optimize chromatographic factors such as temperature, column characteristics and flow rates. Mixture designs are used to vary proportions of mixture ingredients such as the solvent proportions of a mobile phase
\end{abstract}

Key words: Box-Behnken Doehlert, Fractional Factorial Designs, Mixture Designs

Cite this Article: Nilesh Awate and D. J. Tidke, Designing and Optimization of A Mobile Crop Residue Disintegrator by Using Box Behnken RSM Method. International Journal of Design and Manufacturing Technology 7(2), 2016, pp. 1-13.

https://iaeme.com/Home/issue/IJDMT?Volume $=7 \&$ Issue $=2$ 


\section{INTRODUCTION}

The present study of design and development of a crop residue mobile disintegrator machine. The main objectives of the research work were to develop a suitable size tractor operated crop residue disintegrator and to study the performance of the machine in actual field conditions with utilizing the optimized blade angle. The present machine was designed and developed by considering the different parameters. On the basis of theoretical considerations and assumptions made on different para meter for selection and development of components of mobile disintegrator machine various reviews taken in account of in the development procedure. As Accordingly the various parts are developed and selected from the market during the development procedure. For optimization of design the cutting blade angle with different speed and load plays a vital role. For this the analysis was made on the combinations of blade angels, impact load and cutting speed and observed the responses on actual force, cutting efficiency and collection efficiency by utilizing the trial version of Design Expert 10.0.2 software for experimental design. The factorial Box-Behnken design matrices method was selected for optimized solution of the blade angle with 17 runs with three variables. By using this software the optimized solution of the blade angle with an impact load at a speed was detrain. Due to this an optimized blade was used for the final prototype development and to Observed the field performance on large field.

\subsection{BOX-BEHNKEN DESIGNS}

Box-Behnken designs constitute an alternative to central composite designs [20]. They are a class of rotatable or nearly rotatable second-order designs based on threelevel incomplete factorial designs. Fig. 1 shows the Box-Behnken design for three factors, corresponding to the coded values listed in Table 1. It is easy to see that this design consists of three parts of four runs. Within each part, two factors are arranged in a full two-level design, while the level of the third factor is set at zero. The points lie on the surface of a sphere centered at the origin of the coordinate system and tangential to the midpoint of each edge of the cube. Compared to the central composite design, this design has some advantages. The three-factor Box-Behnken design requires only 12 runs plus the replicates at the center point, whereas its central composite counterpart has 14 non-center points. In general the number of experimental points is given by $2 k(k-1)+C 0$. Also, each factor is studied at only three levels, an important feature in some experimental situations, as we have already mentioned. On the other hand, using $\alpha=1$ in a central composite design also results in three levels for each factor. In most real applications these differences are probably not decisive in determining which design to use, at least for this number of factors. However, since Box-Behnken designs do not contain combinations where all the factors are at their higher or lower levels, they may be useful in avoiding experiments under extreme conditions, for which unsatisfactory results might occur. Conversely, they are not indicated for situations in which we would like to know the responses at the extremes, that is, at the vertices of the cube. Box-Behnken designs for four and five factors can be arranged in orthogonal blocks, as shown in Table 1. In this table, each $( \pm 1, \pm 1)$ combination within a row represents a full 22 design. Dashed lines separate the different blocks. Because of the block orthogonality, the second-order model can be augmented to include block effects without affecting the parameter estimates, that is, the effects themselves are orthogonal to the block effects. This 
orthogonal blocking is a desirable property when the experiment has to be arranged in blocks and the block effects are likely to be large.

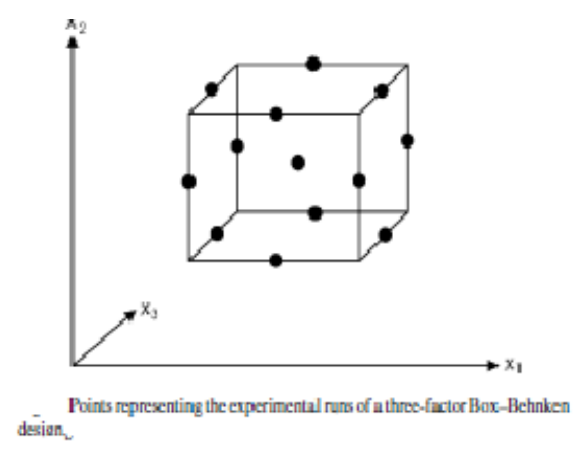

Figure 1 Box Behken design

Table 1 BBD coded level

\begin{tabular}{rrr}
$\begin{array}{l}\text { Table } 3 \\
\text { Coded factor levels for a Box-Behnken design for a three-variable system }\end{array}$ \\
\hline$x_{1}$ & $x_{2}$ & $x_{3}$ \\
\hline-1 & -1 & 0 \\
1 & -1 & 0 \\
-1 & 1 & 0 \\
1 & 1 & 0 \\
-1 & 0 & -1 \\
1 & 0 & -1 \\
-1 & 0 & 1 \\
1 & 0 & 1 \\
0 & -1 & -1 \\
0 & 1 & -1 \\
0 & -1 & 1 \\
0 & 1 & 1 \\
0 & 0 & 0 \\
0 & 0 & 0 \\
0 & 0 & 0 \\
0 & 0 & 0 \\
\hline
\end{tabular}

\section{LITERATURE}

'Sergio Luis Costa Ferreira et. al (2007) describes fundamentals and applications of multivariate statistical techniques for the optimization of chromatographic systems. The surface response methodologies: central composite design, Doehlert matrix and Box-Behnken design are discussed and applications of these techniques for optimization of sample preparation steps (extractions) and determination of experimental conditions.

Box-Behnken designs for four and five factors can be arranged in orthogonal blocks, as shown in Table 1 . In this table, each $( \pm 1, \pm 1)$ combination within a row represents a full 22 design.

M Manohar et. al (2013) have reported that the use of Box Behnken design approach is good for developing Response Surface methodology (RSM) has been adopted to express the output parameters (responses) that are decided by the input process parameters. Box-Behnken design is having the maximum efficiency for an experiment involving three factors and three levels; further, the number of experiments conducted for this is much lesser compared to a central composite design. The proposed BoxBehnken design requires 15 runs of experiment for data acquisition and modeling the response surface. Box Behnken design was successfully adopted and the experiments were designed choosing the input variables for the levels selected. With minimum 
number of experiments, data was collected and the models were developed. Response Surface Models evolved for responses show the effect of each input parameter and its interaction with other parameters, depicting the trend of response.

Perincek Oguz and Colak Metin (2013) It was reported that the BBD model provided an excellent explanation of the relationship among the number of loads and the net harmonic currentsThe results of experiments confirmed that the Box-Behnken experimental design can be used for the determination of loads responsibility and interactions of loads $(\mathrm{A} \times \mathrm{B}, \mathrm{A} \times \mathrm{C}, \mathrm{B} \times \mathrm{C}$, etc. $)$ for the $3^{\text {rd }}$ and $5^{\text {th }}$ harmonic currents.

Myalowenkosi I. Sabela (2014), In this study a Box-Behnken design with fifteen runs, three independent variables $\left(\mathrm{pH}\right.$, concentration of $\mathrm{NH}_{4} \mathrm{Cl}-\mathrm{NH}_{4} \mathrm{OH}$ and APDC) and three replicates at a centre point was used in this study. The experiment was randomized to reduce confounding variables by equalizing the three independent variables that have not been accounted for in the experimental design

Ramesh rudrapati etl (2015).In this work mathematical modeling has been doe by response surface method (RSM). In this study BBD with three factors, three level, and 15 runs are selected. In the BBD matrix the experiment consist of asset of poinint lying at the midpoint of each edge and replicated center point of multidimensional cube.

\section{DATA ANALYSIS AND OPTIMIZATION}

Regression analysis and analysis of variance (ANOVA) were conducted for fitting the models represented by Eq. 4.2 to examine the statistical significance of the model terms. The adequacy of the models were determined using model analysis, lack of fit test and $\mathrm{R}^{2}$ (coefficient of determination) analysis. The lack of fit is a measure of failure of a model to represent data in the experiment domain at which at which points were not included in the regression or variations in the models cannot be accounted for by random error. If there is a significant lack of fit, as indicated by a low probability value, the response predictor is discarded. The $\mathrm{R}^{2}$ is defined as the ratio of the explained variation to the total variation and is a measure of the degree of fit. Coefficient of variation (CV) indicates the relative dispersion of the experimental points from the prediction of the model. Response surfaces and contour plots were generated with the help of commercial statistical package, Design Expert-version 10.0.2. The numerical and graphical optimization was also performed by the same software

\section{OPTIMIZATION PERFORMANCE EVALUATION OF CROP RESIDUE MOBILE DISINTEGRATOR MACHINE}

The field tests were conducted with a range of moisture content $31.16 \%$ to $34.18 \%$. The cotton stalk density represents wider range of crop residue that was usually encountered in field conditions. The various size of cotton stalk was available in the plot while conducting the trials but the maximum size of 20.12. The size of plot has been selected to $25 \mathrm{~m} \times 25 \mathrm{~m}$ for maintaining uniformity throughout all the experiment on plot design. Actual cutting force cutting efficiency and collection efficiency for cotton stalk were determined under performance evaluation of mobile disintegrator machine with the variables of cutting blade angel, cutting speed, and impact load. All the experiments were conducted at Cotton Research Station, and Agronomy Deptt. plot of Dr PDKV Akola. The speed of the machine was $2.5 \mathrm{~km} / \mathrm{h}$ to $3 \mathrm{~km} / \mathrm{h}$ with varying speed ratios of rotor requirement. The observations for each experiment were recorded in Table 3 . 
Designing and Optimization of A Mobile Crop Residue Disintegrator by Using Box Behnken RSM Method

Table 2 Effect of blade angle on actual cutting force required speed for cotton stalk cutting mechanism with impact load

\begin{tabular}{|c|c|c|c|c|c|c|}
\hline \multicolumn{7}{|c|}{ Actual Force in N } \\
\hline & \multicolumn{7}{|c|}{ Blade Angle in Degree } & \multicolumn{3}{c|}{ Impact Load N } \\
\hline & 100 & 105 & 110 & 10 & 20 & 30 \\
\hline $\begin{array}{c}\text { Cutting } \\
\text { speed }\end{array}$ & 100 Stalk diameter 20mm \\
\hline 1600 & 12.5 & 10.23 & 9.41 & 10.23 & 9.41 & 10.63 \\
\hline 1800 & 12.95 & 8.84 & 9.15 & 10.95 & 8.78 & 12.82 \\
\hline 2000 & 10.35 & 9.85 & 9.38 & 8.87 & 10.35 & 9.85 \\
\hline
\end{tabular}

From Table 2, it is depicted that the minimum cutting force required with cutting blade angel of $105^{\circ}$ and was observed to be $8.84 \mathrm{~N}$ at, $1800 \mathrm{rpm}$, In above all speed the cutting force required to cut material is less in $105^{\circ}$ blade angle.

Similarly the actual cutting force to be required for the cutting of crop residue with a impact load of $30 \mathrm{~N}$ was10.63, 12.95 and $9.85 \mathrm{~N}$ at 1600,1800, $2000 \mathrm{rpm}$ were recorded. In above all speed the cutting force required to cut material is less in the impact load of $20 \mathrm{~N}$

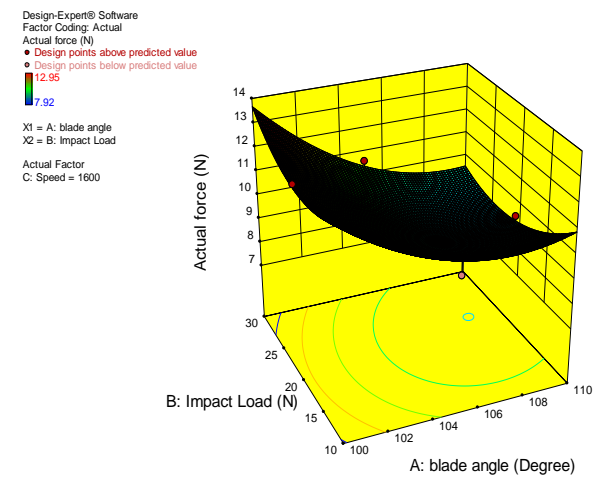

Surface plot for 1600rpm

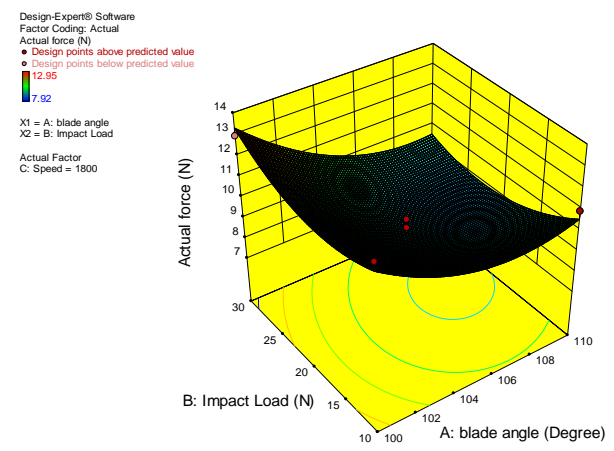

Surface plot 1800rpm
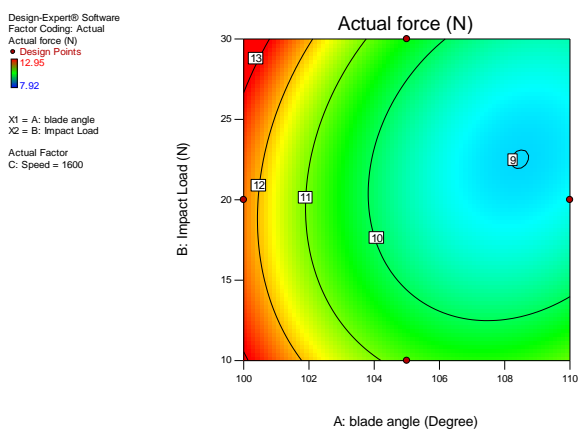

Contour plot for 1600rpm
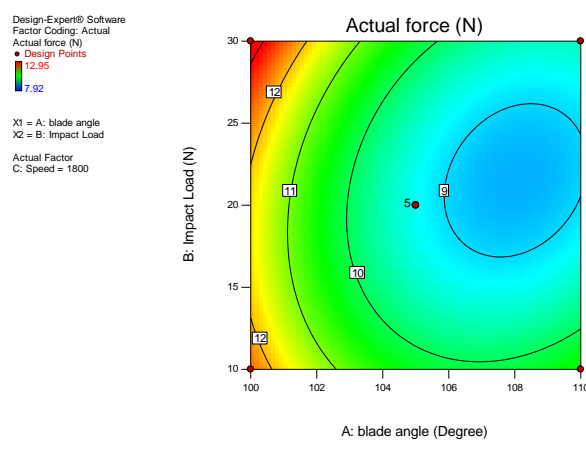

Contour plot for 1800rpm 


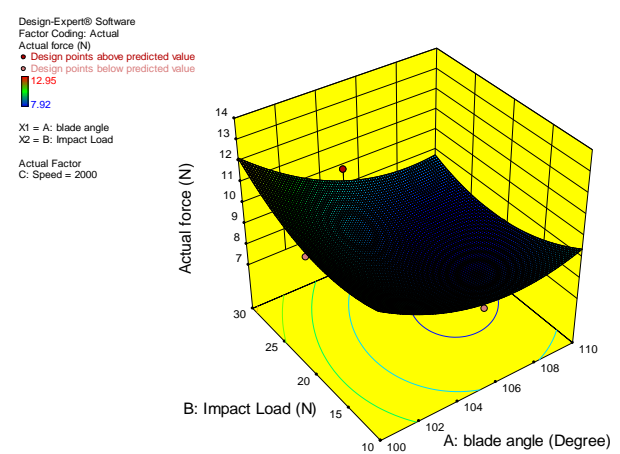

Surface plot for 2000rpm

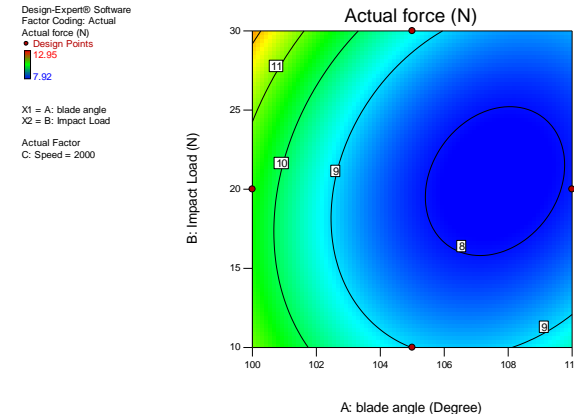

Contour plot for 1600rpm

Figure 2 Effect of blade angle on actual cutting force required speed for cotton stalk cutting mechanism with impact load.

Table 3 Effect of blade angle on cutting efficiency required speed for cotton stalk cutting mechanism with impact load

\begin{tabular}{|c|c|c|c|c|c|c|}
\hline \multicolumn{7}{|c|}{ Cutting Efficiency \% } \\
\hline \multicolumn{7}{|c|}{ Cotton Stalk diameter $20 \mathrm{~mm}$} \\
\hline & \multicolumn{3}{|c|}{ Blade Angle, in Degree } & \multicolumn{3}{|c|}{ Impact Load, $\mathbf{N}$} \\
\hline $\begin{array}{l}\text { Cutting } \\
\text { speed }\end{array}$ & 100 & 105 & 110 & 10 & 20 & 30 \\
\hline 1600 & 96.17 & 95.86 & 94.18 & 95.86 & 94.18 & 98.11 \\
\hline 1800 & 96.92 & 98.38 & 94.9 & 93.18 & 98.58 & 94.9 \\
\hline 2000 & 96.19 & 97.19 & 96.15 & 96.02 & 96.15 & 97.19 \\
\hline
\end{tabular}

From Table 4, it is depicted that the maximum cutting efficiency required with cutting blade angel of $105^{\circ}$ and was observed to be $98.38 \%$ at, $1800 \mathrm{rpm}$, also for same blade angle the cutting efficiency required it is depicted that the maximum cutting efficiency obtained to cut cotton stalk of $20 \mathrm{~mm}$ diameter with impact load of $20 \mathrm{~N}$ was $98.58 \%$ at $1800 \mathrm{rpm}$ were observed in the given table. In above all speed the maximum cutting efficiency obtained after cutting of all crop residue in the impact load of $20 \mathrm{~N}$.

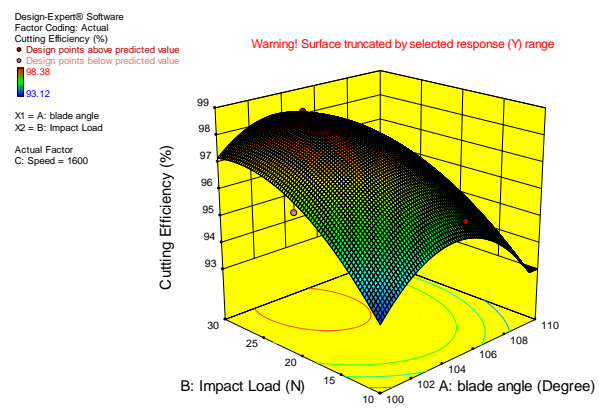

Surface plot 1600rpm
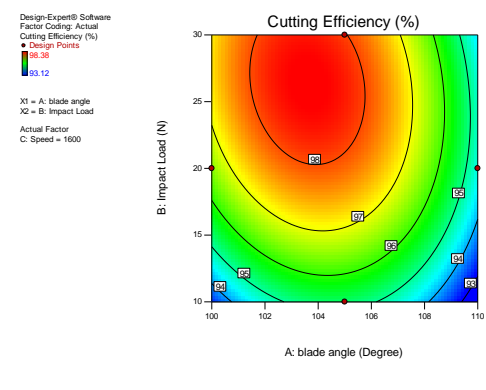

Contour plot 1600 


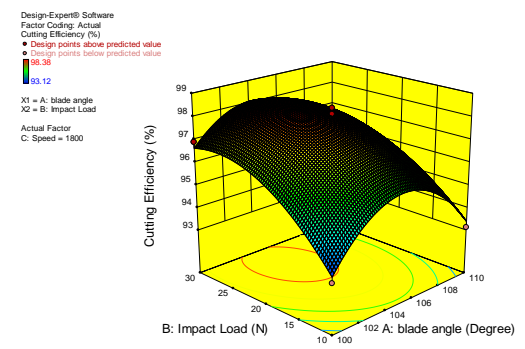

Surface plot 1800

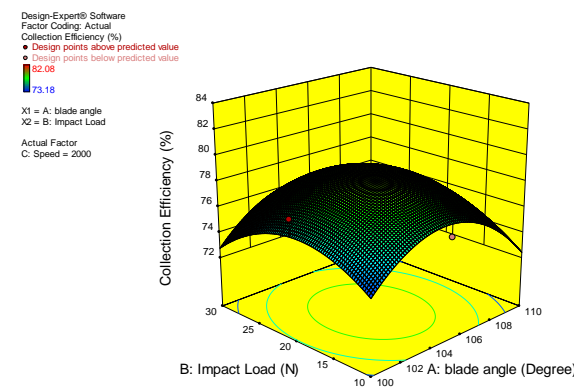

Surface plot 2000rpm
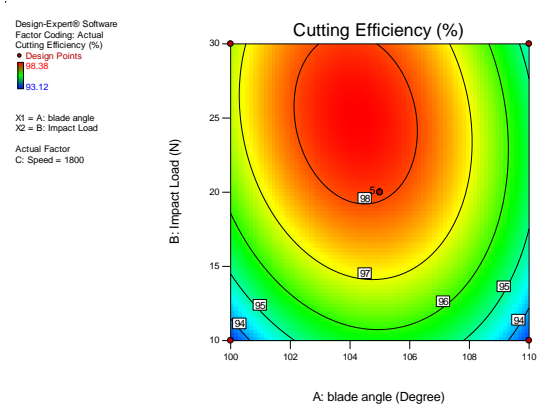

Contour plot 1800
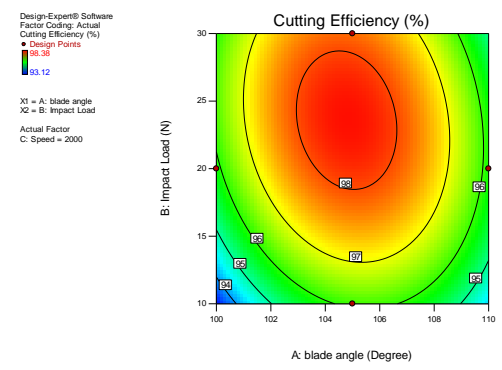

Contour plot 2000rpm

Figure 3 Effect of blade angle on cutting efficiency required speed for cotton stalk cutting mechanism with impact load

Table 4 Effect of blade angle on collection efficiency required speed for cotton stalk cutting mechanism with impact load

\begin{tabular}{|c|c|c|c|c|c|c|}
\hline \multicolumn{7}{|c|}{ Collection Efficiency \% } \\
\hline & \multicolumn{7}{|c|}{ Blade Angle in Degree } & \multicolumn{3}{c|}{ Impact Load N } \\
\hline $\begin{array}{c}\text { Cutting } \\
\text { speed }\end{array}$ & 100 & 105 & 110 & 10 & 20 & 30 \\
\hline 1600 & 75.12 & 77.96 & 73.18 & 76.54 & 75.12 & 77.96 \\
\hline 1800 & 74.98 & 80.8 & 74.18 & 74.95 & 81.35 & 74.84 \\
\hline 2000 & 77.19 & 75.19 & 75.48 & 75.87 & 77.19 & 75.19 \\
\hline
\end{tabular}

It is depicted that the maximum collection efficiency required with cutting blade angel of $105^{\circ}$ and was observed to be $80.85 \%$ at, $1800 \mathrm{rpm}$, In above all speed the collection efficiency obtained after cut material is maximum in $105^{\circ}$ blade angle.

It is depicted that the maximum collection efficiency obtained to cut cotton stalk of $20 \mathrm{~mm}$ diameter with impact load of $20 \mathrm{~N}$ was $81.35 \%$ at $1800 \mathrm{rpm}$ were observed in the given table 5 .

In above all speed the maximum collection efficiency obtained after cutting of all crop residue in the impact load of $20 \mathrm{~N}$. 


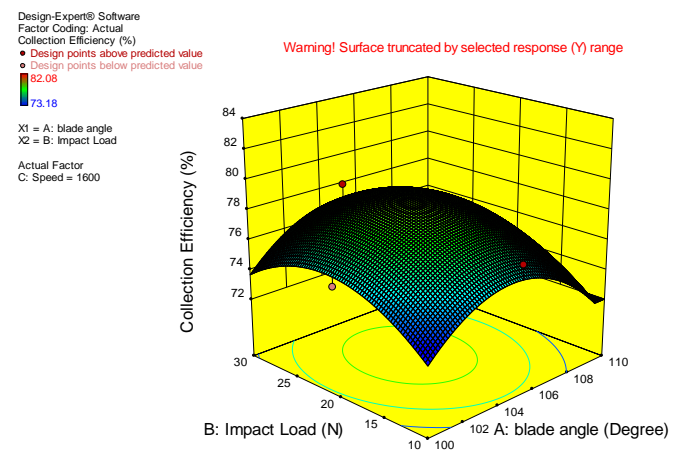

Surface plot for 1600rpm

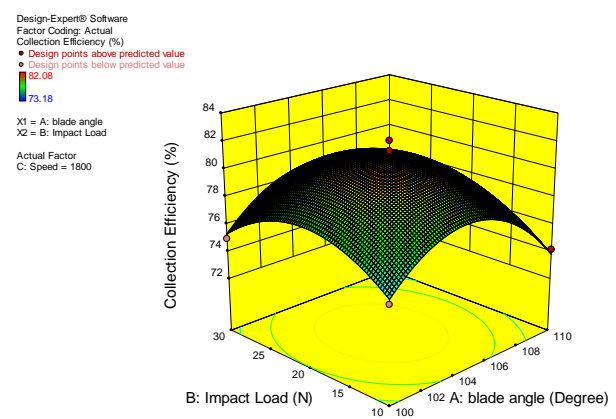

Surface plot 1800rpm

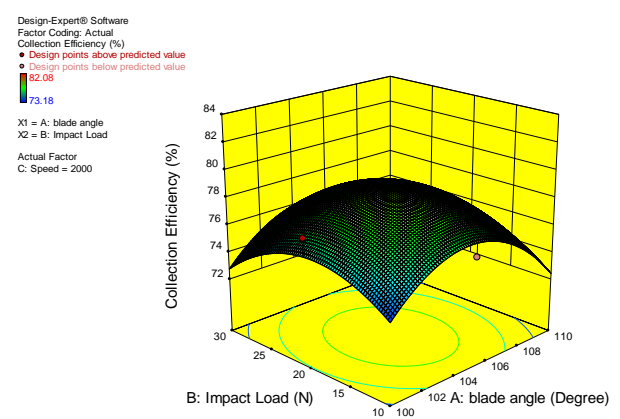

Surface plot for 2000rpm
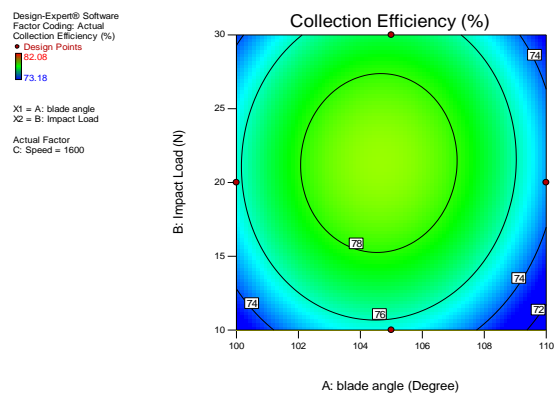

Contour plot 1600rpm
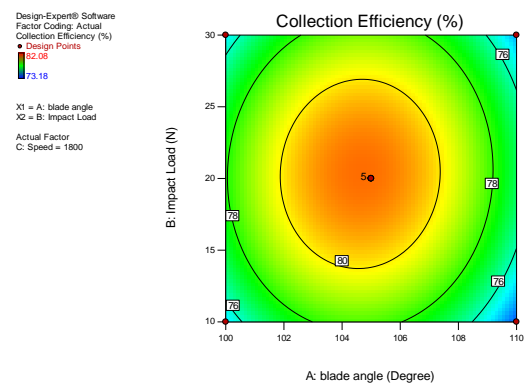

Contour plot for 1800rpm
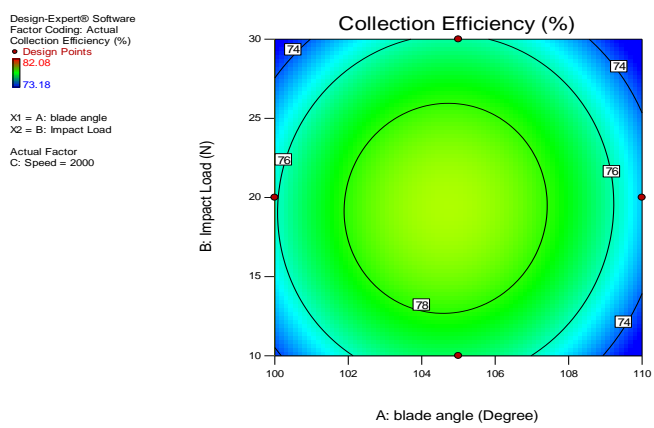

Contour plot 2000rpm

Figure 4 Effect of blade angle on collection efficiency required speed for cotton stalk cutting mechanism with impact load 
Designing and Optimization of A Mobile Crop Residue Disintegrator by Using Box Behnken RSM Method

Table 5 Annova of Annova of cutting force, cutting efficicncy collection effficicny

\begin{tabular}{|c|c|c|c|c|}
\hline Sr & & $\begin{array}{c}\text { Cutting } \\
\text { Force, }\end{array}$ & $\begin{array}{c}\text { Cutting } \\
\text { Efficiency }\end{array}$ & $\begin{array}{c}\text { Collection } \\
\text { Efficiency }\end{array}$ \\
\hline 1 & Model & 0.001 & $0.0003 \mathrm{~S}$ & $0.004 \mathrm{~S}$ \\
\hline 2 & Lack of Fit & $0.12 \mathrm{NS}$ & $0.0158 \mathrm{NS}$ & $0.065 \mathrm{NS}$ \\
\hline 3 & R-Squared & 0.94 & 0.96 & 0.92 \\
\hline 4 & Adj R-Squared & 0.86 & 0.92 & 0.82 \\
\hline 5 & Std. Dev. & 0.53 & 0.49 & 1.23 \\
\hline 6 & Mean & 10.09 & 96.37 & 77.12 \\
\hline
\end{tabular}

\section{ANALYSIS OF VARIANCE}

Regression analysis and analysis of variance (ANOVA) were conducted for fitting the models represented by Eq. 4.2 to examine the statistical significance of the model terms. The adequacy of the models were determined using model analysis, lack of fit test and R2 (coefficient of determination) analysis. The lack of fit is a measure of failure of a model to represent data in the experiment domain at which at which points were not included in the regression or variations in the models cannot be accounted for by random error. If there is a significant lack of fit, as indicated by a low probability value, the response predictor is discarded. The $\mathrm{R} 2$ is defined as the ratio of the explained variation to the total variation and is a measure of the degree of fit. Coefficient of variation (CV) indicates the relative dispersion of the experimental points from the prediction of the model. Response surfaces and contour plots were generated with the help of commercial statistical package, Design Expert-version 10.0.2. The numerical and graphical optimization was also performed by the same software ANOVA has been carried out, with the use of Design Expert-version 10.0.2. software. The results of this analysis are shown in Table 5 (in respect of acceleration of vibration) and in Table 6 (in respect of surface roughness). It is known that if the $\mathrm{P}$ value (significance probability value) is less than 0.05 , the corresponding parameter or variable is considered to be "significant" in influencing the output response, at 95 $\%$ confidence level [29].From Table 5, it is evident that blade angle (A) and its square combination (A2) are "most significant" in the context of the response: acceleration of vibration, as corresponding $\mathrm{P}$ values are zero. The square combination of work speed (C2) is also very significant as its $P$ value is very

\section{RESULTS AND ANALYSIS}

Close to zero. And, individual effect of impact load (B) and its square combination (B2) are found to be significant as relevant $\mathrm{P}$ values are less than 0,05 . The cutting speed (C) and interactions like infeed-longitudinal feed (A x B), infeed-work speed $(\mathrm{A} \times \mathrm{C})$, and longitudinal feed-work speed $(\mathrm{B} \times \mathrm{C})$ do not have significant effect on vibration as their $\mathrm{P}$ values are more than 0.05 .

6.1. Response surface plots Response surface plots arc drawn based on the developed model equations [Eq. 3 for acceleration of vibration and Eq. 4 for machine These plots (and also the earlier contour plots) arc generated for various combinations of the input parameters and different hold values of the third parameter(s). Few of the response surface plots are given in Figs. 2, 3, and 4 for vibration and in Figs. 5, 6, and 7 for surface roughness. Since each model has three variables, one

6.2. Response Contour Plots Contour plots are drawn based on second-order mathematical models Some representative contour plots for cutting force are shown in Figs. 
2, 3, and 4 and for MACHINE in Figs. 5, 6, and 7. These response contours can help in the prediction of the responses at any zone of the experimental domain. Different shades/contrasts have been used in the contour plots, depending on lowest to largest values of the response.

\subsection{Optimization of design parameters for development of straw cutting mechanism}

Numerical and graphical optimization was carried out for independent design parameters of the mobile disintegrator machine to obtain the optimum blade angle with minimum cutting force requirement, to operate at maximum cutting efficiency and collection efficiency. To perform this operation, the Design-Expert software as discussed in section 4.6, was used for simultaneous optimization of the multiple responses. The desired goals for each factor and response were chosen as shown in Table 5.

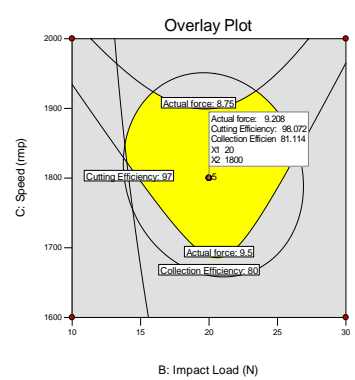

Figure 5 Superimpose contour Graph with desirability

The Superimposed contours of all responses for blade angle and impact load (Fig. 6), for rotating speed. (Fig. 7) and their intersection zone for minimum actual force, maximum cutting efficiency and maximum collection efficiency indicated the ranges of variables which could be considered as the optimum range for best for crop residue mobile disintegrator machine. The ranges of optimum values of independent variables obtained from the superimposed contour are as

Cutting force; $9.2 \mathrm{~N}$ Cutting efficiency: $98.07 \%$ collection efficiency;-81.11 \%

Table 6 Solutions generated by the software for optimum conditions of responses mobile disintegrator machine

\begin{tabular}{|c|c|c|c|c|}
\hline Solutions & & & & \\
\hline Number & $\begin{array}{c}\text { blade } \\
\text { angle }\end{array}$ & $\begin{array}{c}\text { Impact } \\
\text { Load }\end{array}$ & Speed & $\begin{array}{c}\text { Actual } \\
\text { force }\end{array}$ \\
\hline 1 & 105 & 20 & 1800 & 9.208 \\
\hline
\end{tabular}

The above table 6 shows that the software generated optimum conditions of independent variables with the predicted values of responses. Solution number one, having the maximum desirability value (0.92) with minimum blade angle of $9.2 \mathrm{~kg} / \mathrm{ha}$ and $98.207 \%$ cutting efficiency and maximum collection efficiency was selected as the optimum conditions for mobile disintegrator Optimum value of independent variable is obtained by numerical optimization 
Blade Angel:-105 Impact Load;-20N cutting speed:- 1800rpm
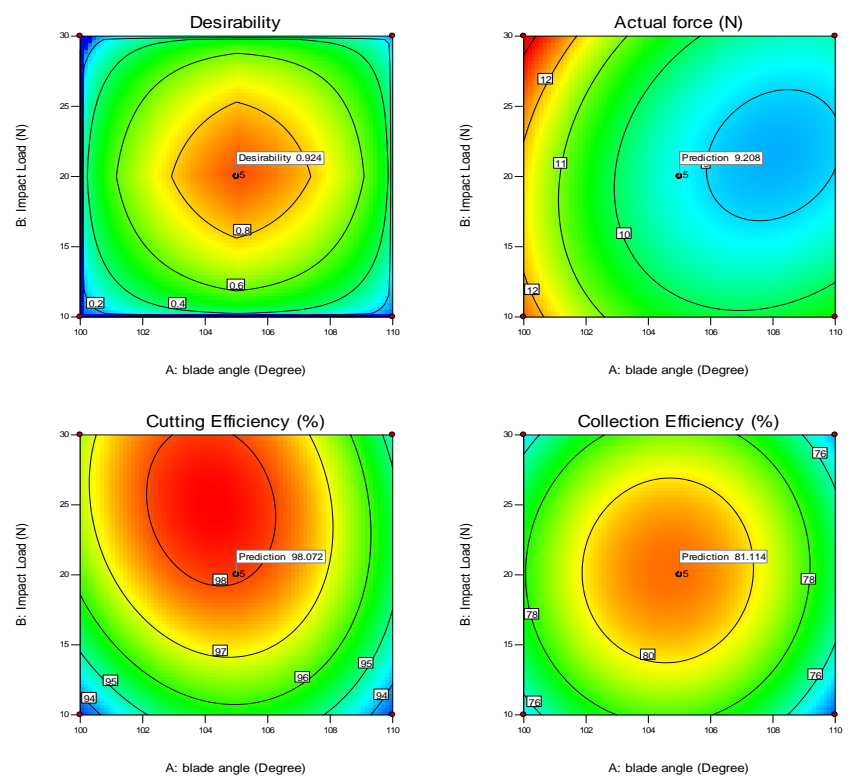

Figure 6

Figure 7

\subsection{Verification of the model for Mobile Disintegrator machine in CRS plot}

The experiments of straw cutting mechanism were conducted at the optimum conditions and straw cutting performance of straw cutting blade were determined. The actual experimental values are given in Annexure A to C. The observed experimental values and predicted by the equations of the model are presented in Table 7 . The predicted values were found to be within acceptable variations ( 0 to 7.01) with the experimental values of the variables of cutting force $(\mathrm{N})$, cutting efficiency\%, collection efficiency \%.( indicated the suitability of the corresponding models.

Table 7 Comparison between predicated and actual response variables at optimum conditions for straw cutting mechanism

\begin{tabular}{|c|l|c|c|c|c|}
\hline Sr No & Responses & Predicted value & Actual Value & & Variation \\
\hline 1 & Actual Force & $9.20 \mathrm{~N}$ & 8.81 & 0.38 & 0.99 \\
\hline 2 & Cutting Efficiency & $98.02 \%$ & 96.17 & 1.34 & 1.88 \\
\hline 3 & Collection Efficiency & 81.11 & 78.75 & 2.36 & 2.90 \\
\hline
\end{tabular}

\subsection{Conducting filed test in the cotton research station plot}

The optimized mobile disintegrator machine with blade angel of $105^{\circ}$ was attaché to the shaft. The machine was operated with the help of tractor PTO at rated RPM to obtaining the optimize speed i.e $1800 \mathrm{rpm}$. The speed of tractor was keep in the range 2.50 to $2.80 \mathrm{Km} / \mathrm{hr}$ for the trials

After comparison with the predicted data with actual value the most of the observation variation is lies in 1 to $3 \%$

\subsection{PFT (PROTOTYPE FIELD TESTING)}

The average filed efficiency of the machine was observed in the range of 90.29 to $92.29 \%$.The cutting efficiency of machine was observed as in the range of 97.18to $97.58 \%$ Where as the average collection efficiency of the machine was observed in 
the range 77.96 to $80.92 \%$. The machine was satisfactory work with easy of operation. The average fuel consumption for the operation was $2.77 \mathrm{lit} / \mathrm{hr}$. and the cost of operation was $917.52 \mathrm{Rs} /$ ha.From the above it was concluded that the machine was works satisfactorily with the 1050 blade angel and at 1800 rpm to obtain the maximum cutting and collection efficiency

\section{CONCLUSION}

\section{THE FOLLOWING CONCLUSIONS ARE MADE FROM THE PRESENT STUDY}

The use of Design Expert 10.0.2 software for experimental design with the factorial Box-Behnken design matrices method was suitable for optimized solution of the blade angle. Which provides the optimized solution of the blade angle of $105^{\circ}$ with an impact load of $20 \mathrm{~N}$ at a speed of $1800 \mathrm{rpm}$. This reduces the efforts required in vast testing procedures with utilizing the all type of blade on the large field.

The software generated optimum conditions of independent variables with the predicted values of responses. Solution number one, having the maximum desirability value (0.92) with minimum blade angle of $9.2 \mathrm{~kg} / \mathrm{ha}$ and $98.207 \%$ cutting efficiency and maximum collection efficiency was selected as the optimum conditions for mobile disintegrator

Contour and surface plots for cutting force, cutting efficiency and collection efficiency of mobile disintegrator machine show that the interactions of input parameters arc prominent for both the responses. These plots may help to predict rcsponsc (s) at some selected parametric combination(s).

The above optimum parametric combination has been validated by confirmatory tests.

\section{REFERENCES}

[1] P. Oguz, C. Metin (2013) Use of Experimental Box-Behnken Design for the Estimation of Interactions Between Harmonic Currents Produced by Single Phase Loads International Journal of Engineering Research and Applications, 3(2), March-April 2013, pp.158-165

[2] Shu, Guowei Chunji Dai, He Chen and Xu Wang (2013)Application of Box-Behnken design in optimization for crude polysaccharides from fruits of Tribulus terristris L. Journal of Chemical and Pharmaceutical Research, 2013, 5(10), pp.342-350.

[3] Sergio Luis Costa Ferreira A, Roy Edward Bruns B, Erik Galvao Paranhos da Silva A,Walter Nei Lopes dos Santos C, Cristina Maria Quintella A M. Jorge David A, Jailson Bittencourt de Andrade A, Marcia Cristina Breitkreitz b, Isabel Cristina Sales Fontes Jardim B, Benicio Barros Neto d (2007), "Statistical designs and response surface techniques for the optimization of chromatographic systems", Journal of Chromatography A, 1158 (2007) pp. 2-14

[4] R. Rodrapati, pal pradip kumar, Bandyopadyay Ashis, (2015) Modeling and optimization of machining parameters in cylindrical grinding process. International journal of manufacturing technology DOI 10.2007/ S00170-015-7500 
[5] S. Myalowenkosi Kanchi Suvardhan, Ayyappa Bathinapatla, Bisetty Krishna (2014) A Box-Behnken Design and Response Surface Approach for the Simultaneous Determination of Chromium (III) and (VI) Using Catalytic Differential Pulse Polarography International Journal of Electrochemical science, Int. J. Electrochem. Sci., 9 (2014) 6751-6764 Received: 5 August 2014 / Accepted: 12 September 2014 / Published: 29 September 201

[6] DC Montgomery (2001) Design and analysis of experiments. Wiley, New York Khayet M, Seman MNA, I lilal N (2010) Response surface modeling and optimization of composite nano-filtration modified membranes. $\mathbf{J}$ Memb Sci 349(1-2), pp. 13-12

[7] Sachin B. Bende and Nilesh P. Awate, Design, Modeling and Analysis of Excavator ARM. International Journal of Design and Manufacturing Technology 4(2), 2013, pp. 14-20.

[8] Nilesh Awate D.J.Tidke, Modeling and Optimization of A Mobile Crop Residue Disintegrator. International Journal of Mechanical Engineering and Technology 7(3), 2016, pp. 320-328

[9] O, Cclep Asian N. Alp I, Tasdemir G (2011) Optimization of some parameters of stirred mill for ultra-fine grinding of refractory $\mathrm{Au} / \mathrm{Ag}$ ores. Powder Technol 208(1):121-127. 